\title{
THE MEASUREMENT AUTOMATION AND OPTIMIZATION THE SYSTEM OF REPRODUCTION AND TRANSFERRING OF THE IMMITANCE UNITS
}

Serhii Kursin Ph.D. in technical sciences, SE «Ukrmetrteststandard», kursin@gmail.com, +380501335825, Oleh Velychko D.Sc. in engineering, professor

Abstract. Provided investigations have shown that for optimization of the impedance measurement metrological support it is necessary to develop the universal precise comparator. The requirements for a universal comparators are defined. The variational method for automation the bridge balancing proposed. The analysis was provided and determined the optimal phase shift variation to calibrate a two-channel vector voltmeter. Metrological characteristics of the created equipment are presented.

Introduction. Set of measured immitance parameters has meant that the system of reproduction and transferring of the units is a complex primary standards and precision comparators, lower standards and working measuring devices [1]. The highest accuracy has primary standards of capacitance and resistance which are based on fundamental constants. However, for the transferring the unit's size from quantum standards to working standards are used unique precision comparators. These comparators operate in narrow ranges in the manual mode [2]. Creation and operation of such equipment requires highly skilled personnel and considerable financial costs. Thus, for the transfer of the unit capacitance and resistance at NIST 8 different comparators uses [3].

Due to the fact that the accuracy and time of measurement for customer in individual cases is essential, the choice of a calibration laboratory creates a competitive edge of metrological centers. This requires the creation of automated equipment and optimization of the reproduction and transferring system of measurement of immitance parameters. The resolving the optimization question - is creating an universal precision immitance comparator and use only one standard of the parameters and frequency standard, as shown in Figure 1.

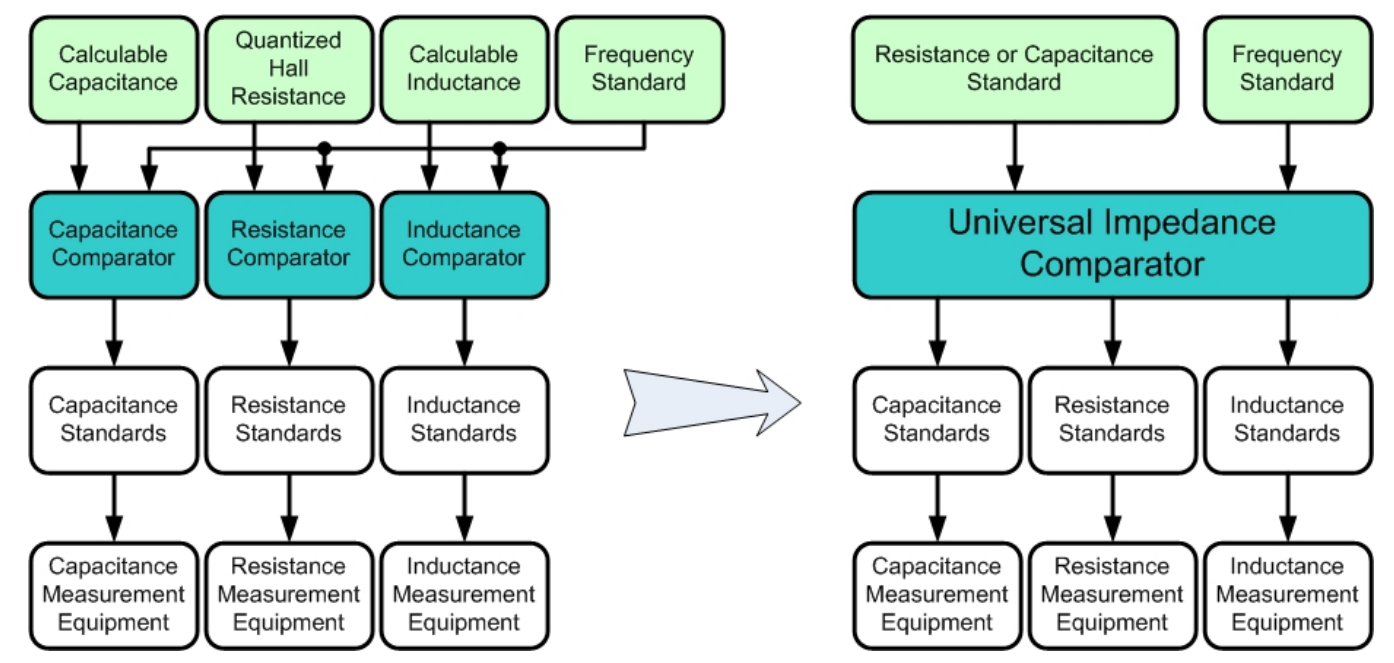

Figure 1. Optimization of the system of transmission parameters immitance size

\section{The main content of research}

The universal comparator must perform the following functions:

- Quadrature comparison (transfer size of unit from the standard of capacitance to the reference standard of resistance and vice versa);

- Antiphase comparison (transfer size of unit from the standard of capacitance to the reference standard of inductance and vice versa);

- Well-nominal comparison of the parameters of standard measures of any kind;

- Decimal comparison of the parameters of standard measures of any kind;

- Comparison parameters of standard measures at an arbitrary value of the auxiliary parameter (tg). 
Developed a set of universal precision comparators that fully meets these requirements, consisting of:

- Autotransformer bridge-comparator which transmits sized units of all parameters in the whole range of impedance values of standard measures;

- Quadrature bridge-comparator which transmits $C \leftrightarrow R$ at low loss tangent and phase angle.

To solve the problem of automatical balancing variational method is using [1]. The method is conducted (in general) by measuring the unbalance signal, make a variation turns one winding, and make a second measuring unbalance signal. Make and solve a system of equations. The result is using to balance the bridge or to find the distance between the current state of the bridge and the state of the ideal balance. It is proposed to use a computer to control the comparators, mathematics calculation, presentation and storage of results.

We use the same vector voltmeter to measuring unbalance signal from both bridges. This decision allows combining two comparators in a common housing.

To improve the performance of equipment in vector voltmeter should be used twochannel structure. Generalized block diagram of the two-channel vector voltmeter shown in Figure 2.

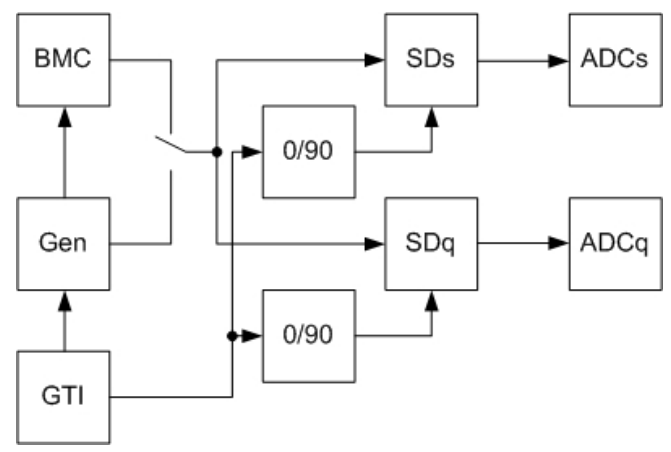

Figure 2. Generalized block diagram of the two-channel vector voltmeter

In measuring inputs of the synchronous detector (in-phase) SDs and (quadrature) SDq served measured signal $U_{x}=U_{m} h \sin (\omega t+\varphi x)$ from the bridge measuring circuit (BMC). In supporting synchronous detector inputs submitted two shifted in phase $90^{\circ}$ reference signal(0/90). The rectified signals from synchronous detector outputs are fed to the analogto-digital converters ADCs and ADCq.

The fact that its channels are nonidentical is taken into account when it is periodically calibrated. [4]. For calibration of the voltmeter to measuring inputs serves the voltage Um from oscillator with frequency $\omega$ and initial phase $\varphi_{o}$, and the supporting synchronous detector inputs served alternately sinusoidal voltage with variation of phase shift $\gamma$. Measure orthogonal components $U 1, U 2, U 3, U 4$ of input voltage $U m$, calculate the ratio of module transmission coefficient of channels $K$ and the phase delay $\Delta \varphi$ between in-phase and quadrature channels. The actual task is to determine the optimal variation of phase shift $\gamma$, where the error of $\mathrm{K}$ is the lowest.

The ratio of the modules transmission coefficient $\mathrm{K}$ of the detectors channels are finding from the system of equations:

$$
\begin{aligned}
& U_{1}=0.5 \cdot U_{m} \cdot K \cdot \sin \left(\omega t+\varphi_{0}\right) \cdot U_{0} \cdot \sin (\omega t) \\
& U_{2}=0.5 \cdot U_{m} \cdot \sin \left(\omega t+\varphi_{0}\right) \cdot U_{0} \cdot \sin (\omega t+\Delta \varphi) \\
& U_{3}=0.5 \cdot U_{m} \cdot K \cdot \sin \left(\omega t+\varphi_{0}\right) \cdot U_{0} \cdot \sin (\omega t+\gamma) \\
& U_{4}=0.5 \cdot U_{m} \cdot \sin \left(\omega t+\varphi_{0}\right) \cdot U_{0} \cdot \sin (\omega t+\Delta \varphi+\gamma)
\end{aligned}
$$

Solution of the system of equations (1) provides find transmission coefficient detectors channels at random variation of phase shift: 


$$
K=\frac{U_{1}}{U_{2}} \cdot\left[\cos (\Delta \varphi)+\left(\frac{U_{3}}{U_{1}}-\cos (\gamma)\right) \cdot \frac{\sin (\Delta \varphi)}{\sin (\gamma)}\right],
$$

To determine the optimal phase shift variation we find in which variation the accuracy of the calibration of the detector will be maximum. Evaluate error ratio determination module of transmission coefficient channels $\mathrm{K}$ depending on the variation of the phase shift. Make replacement: $\cos \Delta \varphi \approx 1-\frac{\Delta \varphi^{2}}{2} \approx 1$. Error of measuring voltages $U 1, U 2, U 3, U 4$ caused by noises one voltmeter, so we can make the assumption that they are equal. Present them as relative $\delta U$. Accordingly, we write the expression for K considering errors:

$$
K \approx \frac{U_{1}}{U_{2}} \cdot\left[1+\left(\frac{U_{3}}{U_{1}}-\cos (\gamma)\right) \cdot \frac{\sin (\Delta \varphi)}{\sin (\gamma)}\right]+\frac{U_{1}}{U_{2}} \cdot\left(1+\frac{U_{3}}{U_{1}}\right) \cdot \delta U_{1} \cdot \frac{\sin (\Delta \varphi)}{\sin (\gamma)}+\delta U_{2} \cdot
$$

We write the expression that characterizes the error ratio determination module of transmission coefficient channels $\mathrm{K}$ :

$$
K \approx \frac{U_{1}}{U_{2}} \cdot\left(1+\frac{U_{3}}{U_{1}}\right) \cdot \delta U_{1} \cdot \frac{\sin (\Delta \varphi)}{\sin (\gamma)}+\delta U_{2} .
$$

From equation (4) it follows that the error of $\mathrm{K}$ will be minimal at $\sin \gamma=1$, or at $\gamma=\pi / 2$. In general, the error of determination $\mathrm{K}$ by variations of angle phase shift is proportional to 1 / siny. So to make variations on the basic inputs of synchronous detector should apply alternately sinusoidal and cosinusoidal voltage Uo.

The component of the vector voltmeters error, defined by equations (2) subsequently used to correct measurement results of the bridge-comparator.

Brief Characteristics of the Comparator:

- Zero shift at the main limits, not greater than $0.5 \cdot 10^{-6}$

- Error of decimal transfer at the main limits, not greater than $0.5 \cdot 10^{-6}$

- Sensitivity threshold of the comparator (without averaging), less than $0.01 \cdot 10^{-6}$

- $C \rightarrow L$ transfer error, not greater than $10 \cdot 10^{-6}$

- Sensitivity threshold of $C \rightarrow L$ transfer (without averaging), less than $0.1 \cdot 10^{-6}$

- Zero shift of the $\mathrm{R} \leftrightarrow \mathrm{C}$ comparator, not greater than $1 \cdot 10^{-6}$

- Sensitivity threshold of the $R \leftrightarrow C$ comparator, less than $0.05 \cdot 10^{-6}$

- Error of direct transmission of the signal of the quantized Hall standard to the $10 \mathrm{k} \Omega$ measure-carrier (during the experimental investigations) $0.2 \cdot 10^{-6}$

- Operating frequencies 1.0 and $1.59 \mathrm{kHz}$

The apparatus described above is functionally capable of reproducing the units of the parameters of impedance and transferring their dimensions, and can also provide a metrological backup for all the parameters of impedance with support, in principle, of only one of the standards of impedance parameters. It has been delivered to GUM, NIST, and BeIGIM, and has been used to construct the State Standard of inductance of the Ukraine.

According to the results of comparisons of the program EUROMET.EM-S20 and EUROMET.EM-S26 use developed complex universal comparators shown in Figure 3a, unlike the combined transformer bridge has enabled the National Meteorological Center of Poland GUM order to reduce the measurement error of inductance and twice reduce uncertainty. According to the results of comparisons of the program COOMET.EM-S14 measurement uncertainty of State Primary Standard unit of inductance and loss tangent (DETU 08/09/09) stored in SE "Ukrmetrteststandart" which is represented in Figure 3b , is $0.02 \mathrm{mH} / \mathrm{H}[5-6]$. 


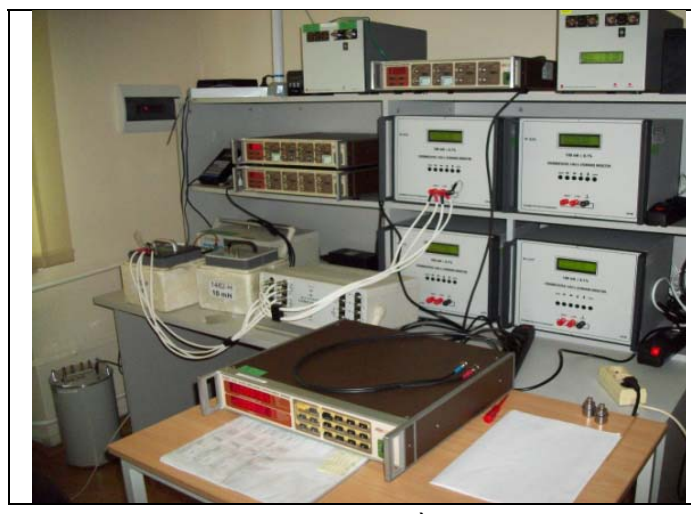

a)

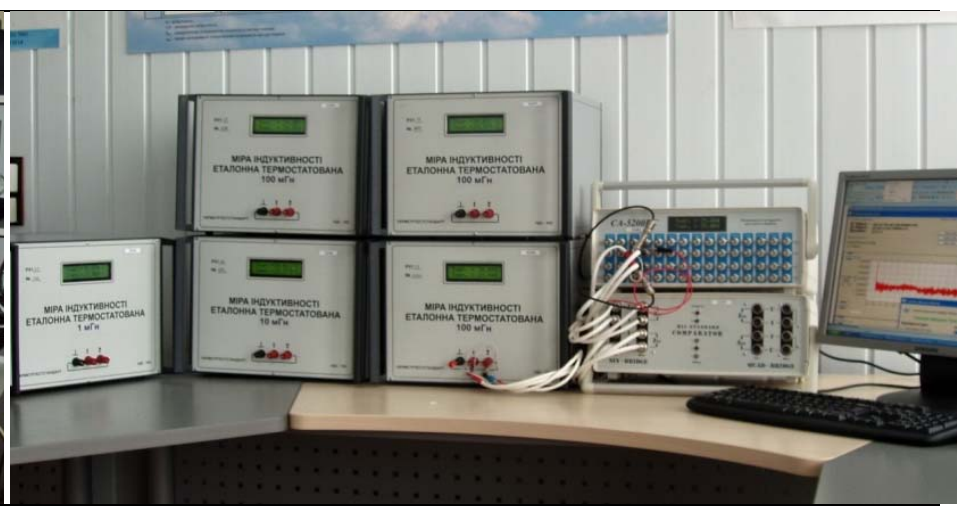

b)

Figure 3 Complex equipment: a) GUM (Poland), b) DETU 08-09-09 (Ukraine)

\section{Conclusions}

It is shown that in general, the error of $\mathrm{K}$ caused by variations of angle phase shift is proportional to $1 /$ siny. To reduce the error proposed supporting inputs of synchronous detector alternately sinusoidal and cosine voltage. The methodology for implementation of precision measurement and automation of electrical measurements proposed.

The optimizing system of reproduction and transferring of the immitance units enable the metrological laboratory to significantly reduce the costs of creating and storing standards, reduce the range of standards and equipment. So, therefore, increase in competitiveness through lower cost of operations of calibration and verification provide.

1. M. Surdu An automatic bridge for the comparison of the impedance Standards / $M$. Surdu , A. Lameko, D. Surdu, S. Kursin// Measurement. - 2013. - №46. - p. 37013707.

2. S. W. Chua, B. P. Kibble, and A. Hartland, "Comparison of capacitance with AC quantized Hall resistance," Precision Electromagnetic Measurements: Digest Conf., Washington, DC, USA (1998), pp. 418-419.

3. Jeffery A. Determination of the von Klitzing constant and the fine structure constant through a comparison of the quantized Hall resistance and the ohm derived from the NIST calculable capacitor / A. Jeffery, R. E. Elmquist, J. Q. Shields, L. H. Lee, M. E. Cage, S. H. Shields, and R. F. Dziuba // Metrologia, 1998. - 35(2). - P. 83-96.

4. Сурду М. Н. Особенности калибровки двухканального векторного вольтметра цифрового моста переменного тока / М. Н. Сурду, А. Л. Ламеко, М. Я. Мухаровский, И. В. Карпов, С.Н.Курсин // Український метрологічний журнал. 2011. - № 1. - C. 25-29.

5. EUROMET.EM-S26: Final Report of EURAMET.EM-S26 Supplementary Comparison Inductance measurements of $100 \mathrm{mH}$ at $1 \mathrm{kHz}$ EURAMET project 816, ver. 2011-12-
113
[Електронний
pecypc]
Режим доступу

http://www.bipm.org/utils/common/pdf/final_reports/EM/S26/EUROMET.EM-S26.pdf.

6. COOMET.EM-S14: Final Report on COOMET Supplementary Comparison of Inductance at $10 \mathrm{mH}$ and $100 \mathrm{mH}$ at $1 \mathrm{kHz}$, July 2015 [Електронний ресурс] - Режим доступу : http://www.ukrcsm.kiev.ua/files/COOMET.EM-S14.pdf 